\title{
Thermo-rheological properties of coal-tar pitch modified with phenol-formaldehyde resin
}

\author{
Wiesława Ciesińska ${ }^{1}$
}

Received: 30 November 2016/Accepted: 19 May 2017/Published online: 5 June 2017

(c) The Author(s) 2017. This article is an open access publication

\begin{abstract}
Test results of changing the thermo-rheological properties of coal-tar pitch under influence of phenolformaldehyde resin are presented in this research work. Influence of modifying agent amount and crosslinking conditions (time) of resin in bitumen was evaluated. Tests were carried out using the rheometer in oscillation mode. They enabled the evaluation of changes in bitumen viscous and elastic properties and draw the conclusions about changes in bitumen structure on that basis. Compositions of the coal-tar pitch with phenol-formaldehyde resin show increased thermal and mechanical resistance. Furthermore, phenol-formaldehyde resin has an effect on increase in the coal-tar pitch viscosity. It probably results from the increased content of components of higher average molecular mass in the pitch and lower solubility in organic solvents.
\end{abstract}

Keywords Coal-tar pitch - Modification · Phenolformaldehyde resin $\cdot$ Thermal resistance $\cdot$ Rheological properties

\section{Introduction}

Coal and products of its chemical processing, such as coaltar distillation residues, are important raw materials for the production of high-quality coal materials. Unfortunately, high content of cancerogenic aromatic compounds makes

Wiesława Ciesińska

Wieslawa.Ciesinska@pw.edu.pl

1 Faculty of Civil Engineering, Mechanics and Petrochemistry, Institute of Chemistry, Warsaw University of Technology, Lukasiewicza 17, 09-400 Plock, Poland that they are acknowledged as the substances of high harmfulness. However, it is difficult to replace coal-tar pitches, among others, in some applications. Therefore, attempts to modify the coal bitumen to decrease its cancerogenicity and to improve technological and quality properties have been done for many years. Such possibilities are provided by modification of coal bitumen with polymers [1-3], among others.

Viscosity and elasticity of bituminous substances and their changes versus temperature are important properties from technological point of view and suitability as the raw material for the production of high-quality coal materials. Coal bitumen for the production of carbon fibres, for instance, should be characterized by appropriate flow ability at fibre-forming conditions [4-6]. Viscoelastic properties of coal material determine the process of forming, growing and merging the pores during carbonizing [7] when bituminous substances are used as the promotor of porous materials.

It is essential that coal material has high fluidity (low viscosity) in carbonizing conditions and that produced cellular material has suitable mechanical strength after carbonizing process.

Addition of polymers to coal bitumen can cause different changes in bitumen properties depending on type of modifying agent and conditions of modification reaction. Use of polyesters [8-10] as modifying agents can be an example. Modification of coal-tar pitch with unsaturated polyester resins leads to considerable plasticization, and such modified bitumens of significantly lower cancerogenicity can be used as binders with insulating and sealing properties. The coal-tar pitch with the addition of poly (ethylene terephthalate) or polycarbonate is characterized by increased thermal and mechanical resistance [10], and it can be used as a promotor of porous materials of great 
specific surface [11-13]. Thermal factor played a decisive role in all examinations. Therefore, changes in properties of pitch-polymer compositions in a broad range of temperatures from 90 to $300{ }^{\circ} \mathrm{C}$ were measured. Significant thermal resistance shows phenol-formaldehyde resin. Such kind of polymer finds different applications. [14-17] Blends of this polymer with other substance can be used for the preparation of carbon-mineral materials, for example. [17]

Testing was aimed at the evaluation of thermal and rheological properties of coal-tar pitch modified with phenol-formaldehyde resin and indication of possible application(s) of such type of materials.

\section{Experimental}

The following raw materials were used in tests:

- granulated coal-tar pitch (Pitch), of softening point $107{ }^{\circ} \mathrm{C}$, received from Institute for Chemical Processing of Coal in Zabrze (Poland),

- phenol-formaldehyde resin (PF) of novolac type, of softening point $101.5^{\circ} \mathrm{C}$, originating from "Organika Sarzyna” S.A. in Nowa Sarzyna (Poland).

Additionally, hexamine as crosslinking agent was used.

The composition of coal-tar pitch with phenolformaldehyde resin was prepared by homogenization of melted constituents at temperature of $140-160{ }^{\circ} \mathrm{C}$ for $0.5 \mathrm{~h}$.

In the case of additionally crosslinked compositions, $2 \%$ of hexamine by mass (in relation to resin) was added and crosslinked in temperature of $160{ }^{\circ} \mathrm{C}$ for $0.5-2.0 \mathrm{~h}$ after homogenization of the pitch with resin. Constituents and conditions of the preparation of individual compositions are presented in Table 1.

Changes in properties of coal-tar pitch under the influence of phenol-formaldehyde resin were evaluated on the basis of:
- $\quad$ softening temperature $\left(T_{\mathrm{R} \& \mathrm{~B}}\right)$ determined by means of "ring-and-ball" method in accordance with PN-EN 1427 standard,

- content of insoluble constituents in quinoline (QI) as per PN-C-97058:1999 standard,

- rheological properties determined by means of AR 200 Rheometer (TA Instrument Inc.). Measurements were taken using parallel plates fixture (plate radius $25 \mathrm{~mm}$; gap between the plates $1 \mathrm{~mm}$ ). Tests were conducted in oscillation mode by determining dependences of storage and loss modules, complex viscosity, phase angle versus frequency $(0.001-50 \mathrm{~Hz})$ and temperature $\left(90-320{ }^{\circ} \mathrm{C}\right)$. Measurements versus temperature were taken by rising the temperature in increments of $5{ }^{\circ} \mathrm{C} \mathrm{min}-1$, at frequency of $1 \mathrm{~Hz}$ and deformation of $0.5 \%$. All oscillation measurements were taken within the linear viscoelasticity region.

\section{Results}

Phenol-formaldehyde resin belongs to duroplastic materials which under the influence of temperature and/or additional substances undergo crosslinking reaction, and in the result hardened resin becomes non-melting and insoluble. Tests to determine changes in the coal-tar pitch properties under the influence of phenol-formaldehyde resin were carried out by evaluating the impact of modifying agent amount and crosslinking time of resin in bitumen.

In order to determine an impact of phenol-formaldehyde resin on properties of coal-tar pitch, the compounds of pitch with 25 and $50 \%$ by mass of modifying agent were prepared by homogenization without crosslinking. Amounts of resin added to pitch were chosen based on previous tests [11]. Minimum 25\% of phenol-formaldehyde resin by mass added to the pitch caused distinct changes in main physical and chemical properties in relation to unmodified pitch $[11,12]$.

Table 1 Composition, crosslinking conditions and physical-chemical properties of the pitch-phenol-formaldehyde compound

\begin{tabular}{|c|c|c|c|c|c|c|c|}
\hline \multirow[t]{2}{*}{ No. of sample } & \multirow[t]{2}{*}{ Symbol of compound } & \multicolumn{3}{|c|}{ Composition of compound/mass $\%$} & \multirow[t]{2}{*}{ Crosslinking time/h } & \multicolumn{2}{|l|}{ Properties } \\
\hline & & Coal-tar pitch & $\mathrm{PF}$ & Hexamine & & $\mathrm{T}_{\mathrm{R} \& \mathrm{~B}} /{ }^{\circ} \mathrm{C}$ & QI/mass $\%$ \\
\hline 1 & Pitch & 100 & - & - & - & 107 & 7.14 \\
\hline 2 & $\mathrm{Pitch} / 25 \mathrm{PF} / 0$ & 75 & 25 & - & 0.0 & 109 & 6.07 \\
\hline 3 & Pitch/25PF/0.5 & 75 & 25 & $2 *$ & 0.5 & 118 & 7.71 \\
\hline 4 & Pitch/25PF/1.0 & 75 & 25 & $2 *$ & 1.0 & 124 & 8.53 \\
\hline 5 & $\mathrm{Pitch} / 25 \mathrm{PF} / 2.0$ & 75 & 25 & $2 *$ & 2.0 & 141 & 10.14 \\
\hline 6 & $\mathrm{Pitch} / 50 \mathrm{PF} / 0$ & 50 & 50 & - & 0.0 & 118 & 8.23 \\
\hline 7 & Pitch/50PF/2.0 & 50 & 50 & $2 *$ & 2.0 & $* *$ & 12.36 \\
\hline
\end{tabular}

* $2 \%$ by mass in relation to phenol-formaldehyde resin

** Non-melting sample, inability to form the sample for testing 
Physical and chemical properties of the coal-tar pitch and pitch-phenol-formaldehyde resin composition are shown in Table 1.

Addition of phenol-formaldehyde resin caused slight increase in softening temperature and distinct increase in share of constituents insoluble in quinoline, which phenomena were becoming more intense along with the increase in resin amount added to the pitch and indicated the change in colloidal structure of the pitch. Tests of rheological properties in oscillation mode with frequency sweep were carried out in order to confirm changes in colloidal structure of bitumen. Tests of such type enable the indication of differences in the structure of structural units of the substance, among others.

It was decided to measure the changes in viscoelastic properties versus frequency of coal-tar pitch and pitchphenol-formaldehyde resin compounds (without crosslinking) at as low as possible temperature $\left(109{ }^{\circ} \mathrm{C}\right)$ which reduces to minimum the possibility of crosslinking reaction during measurement. Runs of chosen dependences are presented in Figs. 1-4.

By comparing the runs of dependences of storage and loss modules versus frequency (Fig. 1) of the coal-tar pitch and compounds of the coal-tar pitch with phenolformaldehyde resin, which did not undergo crosslinking, it was found that they assume analogical runs. In the range of higher frequencies, values of loss modulus were higher than of storage modulus. In the range of lower frequencies, values of both modules became equal. Such arrangement of curves in the case of non-Newtonian liquids suggests that frequency change was accompanied by the transition from transition region to glassy region. [18] Coordinates of intersection points of $G^{\prime}, G^{\prime \prime}=f(v)$ dependence for individual arrangements are included in Table 2.

Intersection point of $G^{\prime}, G^{\prime \prime}=f(v)$ curves determined for the coal-tar pitch was present at highest frequency in
Table 2 Coordinates of intersection points of $G^{\prime}, G^{\prime \prime}=f(v)$ dependence determined for the pitch and compounds of the pitch with phenol-formaldehyde resin

\begin{tabular}{|c|c|c|c|}
\hline \multirow[t]{2}{*}{$\begin{array}{l}\text { Symbol of } \\
\text { compound }\end{array}$} & \multirow[t]{2}{*}{$\begin{array}{l}\text { Measurement } \\
\text { temperature } /{ }^{\circ} \mathrm{C}\end{array}$} & \multicolumn{2}{|c|}{$\begin{array}{l}\text { Coordinates of intersection } \\
\text { points } G^{\prime}, G^{\prime \prime}=f(v)\end{array}$} \\
\hline & & Frequency/Hz & $G^{\prime}=G^{\prime \prime} / \mathrm{Pa}$ \\
\hline Coal-tar pitch & 109 & 0.025 & 789 \\
\hline $\mathrm{Pitch} / 25 \mathrm{PF} / 0$ & 109 & 0.009 & 1298 \\
\hline Pitch/50PF/0 & 109 & 0.003 & 677 \\
\hline $\mathrm{Pitch} / 25 \mathrm{PF} / 0$ & 118 & 0.031 & 853 \\
\hline Pitch/25PF/0.5 & 118 & 0.016 & 1435 \\
\hline Pitch/25PF/1.0 & 118 & 0.004 & 1663 \\
\hline
\end{tabular}

comparison with points determined for the compounds. In the case of compounds, intersection point moved towards lower frequencies together with increase in modifying agent content. It can prove a difference between relaxation times of tested coal-tar pitch and composition. Higher values of storage module determined for the compounds showed higher mechanical resistance of compounds in comparison with the coal-tar pitch.

During the evaluation of complex viscosity (Fig. 2), it was found that the compounds which did not undergo crosslinking demonstrated higher viscosity in comparison with the coal-tar pitch in the whole frequency range at temperature $109{ }^{\circ} \mathrm{C}$. One can also assume that viscosity was insignificantly increased with the increase in resin content in the compound.

The frequency relationships of phase angle and loss tangent ( $\operatorname{tg} \delta=G^{\prime \prime}=G^{\prime}$ ) (Figs. 3, 4) show small differences of viscoelastic properties of coal-tar pitch and the compound containing $25 \%$ of phenol-formaldehyde resin by mass. Slightly bigger changes, especially concerning the loss tangent versus frequency, were noticed in the case of
Fig. 1 The plots of storage $\left(G^{\prime}\right)$ and loss $\left(G^{\prime \prime}\right)$ modules versus frequency determined at temperature $109{ }^{\circ} \mathrm{C}$ for coal-tar pitch and compounds of the coal-tar pitch with phenolformaldehyde resin (without crosslinking): filled circlepitch $\left(G^{\prime}\right)$, open circle-pitch $\left(G^{\prime \prime}\right)$, filled square- $\mathrm{pitch} / 25 \mathrm{PF} /$ $0\left(G^{\prime}\right)$, open square - pitch/ 25PF/0 $\left(G^{\prime \prime}\right)$, open trianglepitch/50PF/0 $\left(G^{\prime}\right)$, filled triangle - pitch/50PF/0 $\left(G^{\prime \prime}\right)$

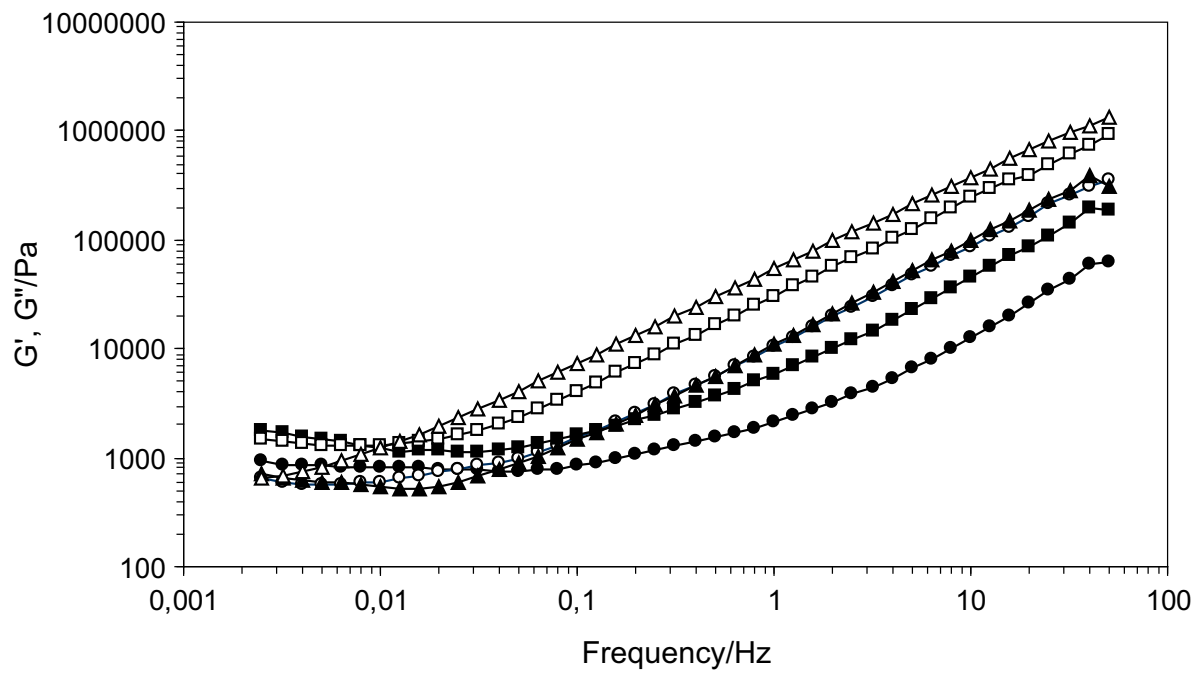



viscosity $\left(\left|\eta^{*}\right|\right)$ versus frequency, determined at temperature $109{ }^{\circ} \mathrm{C}$ for coal-tar pitch and compounds of the coal-tar pitch with phenolformaldehyde resin (without crosslinking): open circlepitch, open square - pitch/ $25 \mathrm{PF} / 0$, open triangle - pitch/ $50 \mathrm{PF} / 0$
Fig. 2 The plots of complex

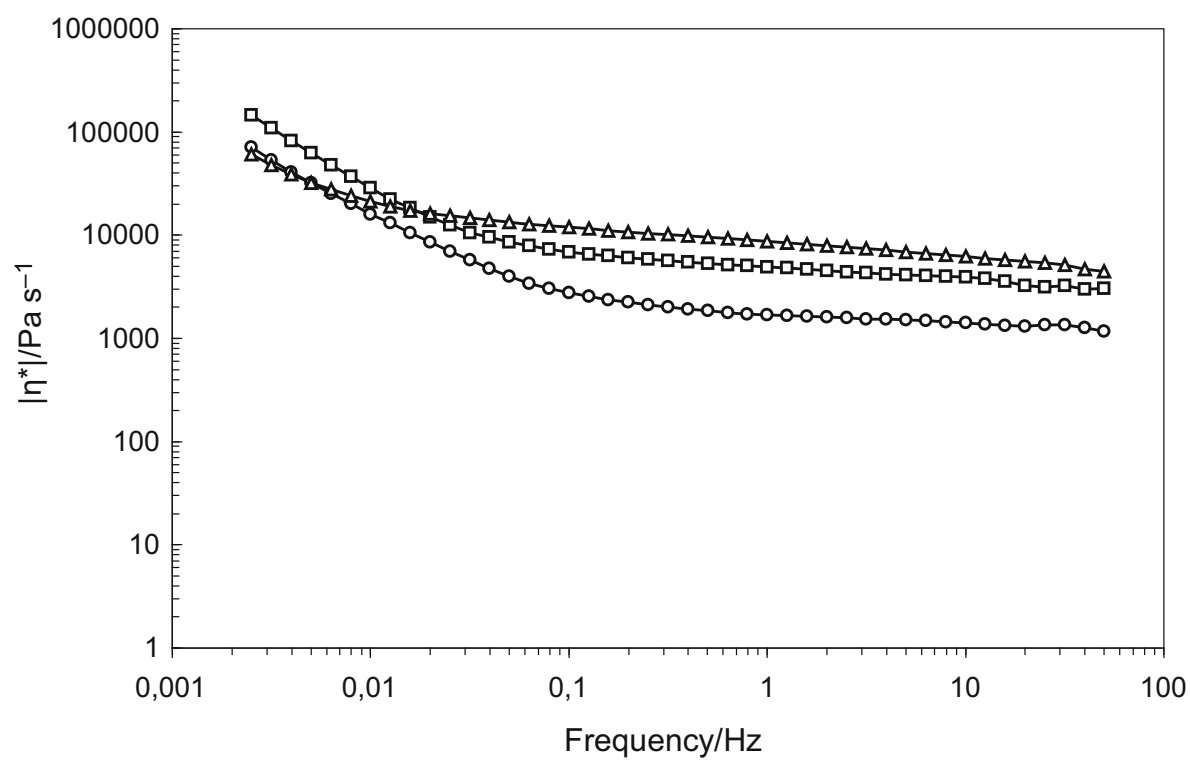

Fig. 3 The plots of phase angle $(\delta)$ versus frequency, determined at temperature $109{ }^{\circ} \mathrm{C}$ for coal-tar pitch and compounds of the coal-tar pitch with phenol-formaldehyde resin (without crosslinking): open circle - pitch, open squarepitch/25PF/0, open triangle$\mathrm{pitch} / 50 \mathrm{PF} / 0$

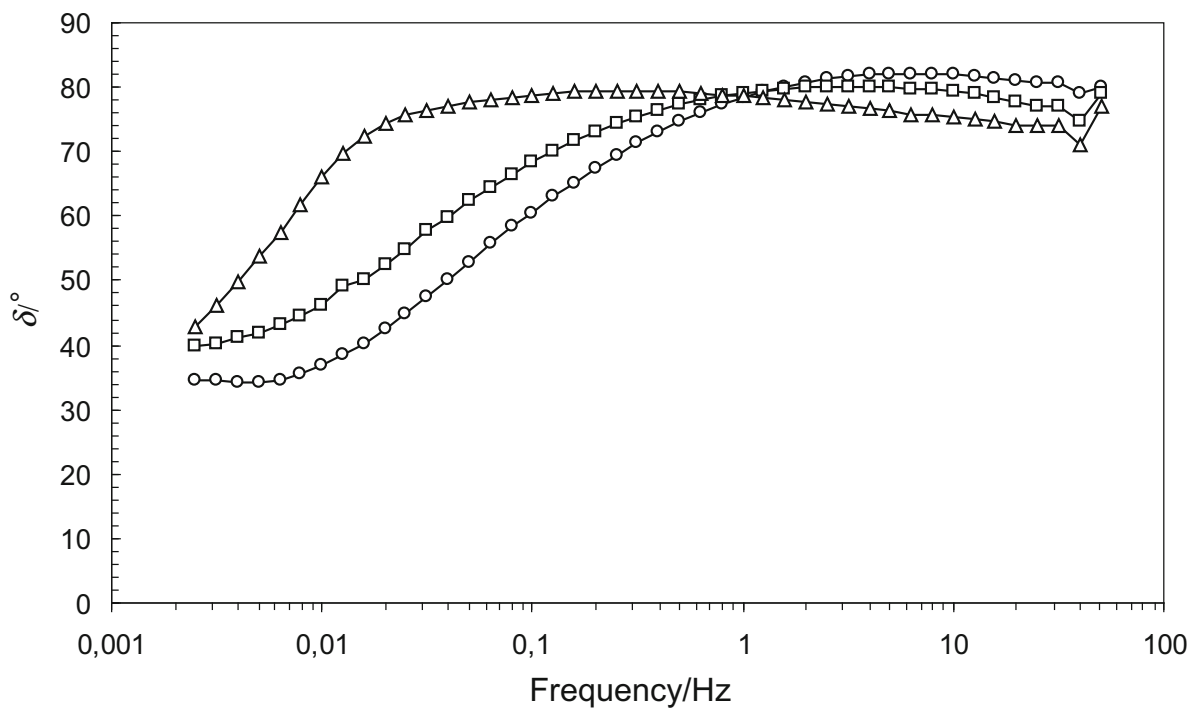

coal-tar pitch. The coal-tar pitch and compound containing $25 \%$ of resin by mass showed highest ability to dissipate energy at highest frequencies, i.e. during acting of load of short duration.

Predominance of viscous properties was observed for compounds containing 50\% of phenol-formaldehyde resin practically in the whole frequency range. At frequencies lower than $0.01 \mathrm{~Hz}$, the system showed more visible elastic characteristics (Fig. 3). Differences were also observed for the run of loss tangent versus frequency. The compound containing $50 \%$ of modifying agent by mass demonstrated higher ability of energy dissipation at frequencies up to $1 \mathrm{~Hz}$ (Fig. 4).

To conclude, addition of phenol-formaldehyde resin to coal-tar pitch caused the increase in softening temperature, content of components insoluble in quinoline, value of complex viscosity and storage and loss modulus. Such trend of property changes can point at the change in colloidal structure of bitumen under influence of resin, which probably results from interactions between components of the coal-tar pitch and phenol-formaldehyde resin at the stage of homogenization of components at temperature $160{ }^{\circ} \mathrm{C}$ and the probable formation of components of lower solubility in organic solvents. Mechanism of such interactions can include, among others, reactions between phenolic resin molecules and methylene groups in coal-tar pitch, as described by Li et al. [19]. Direct connection of polyaromatic hydrocarbon molecules with aldehyde carbon atoms of phenolic resin is also possible. Reaction of such type could probably lead to the partial crosslinking of resin added to pitch and the change in bitumen properties. At the same time, phenol-formaldehyde resin of melting 
Fig. 4 The plots of loss tangent $(\operatorname{tg} \delta$ ) versus frequency, determined at temperature $109{ }^{\circ} \mathrm{C}$ for coal-tar pitch and compounds of the coal-tar pitch with phenol-formaldehyde resin (without crosslinking): open circle - pitch, open square$\mathrm{pitch} / 25 \mathrm{PF} / 0$, open trianglepitch/50PF/0

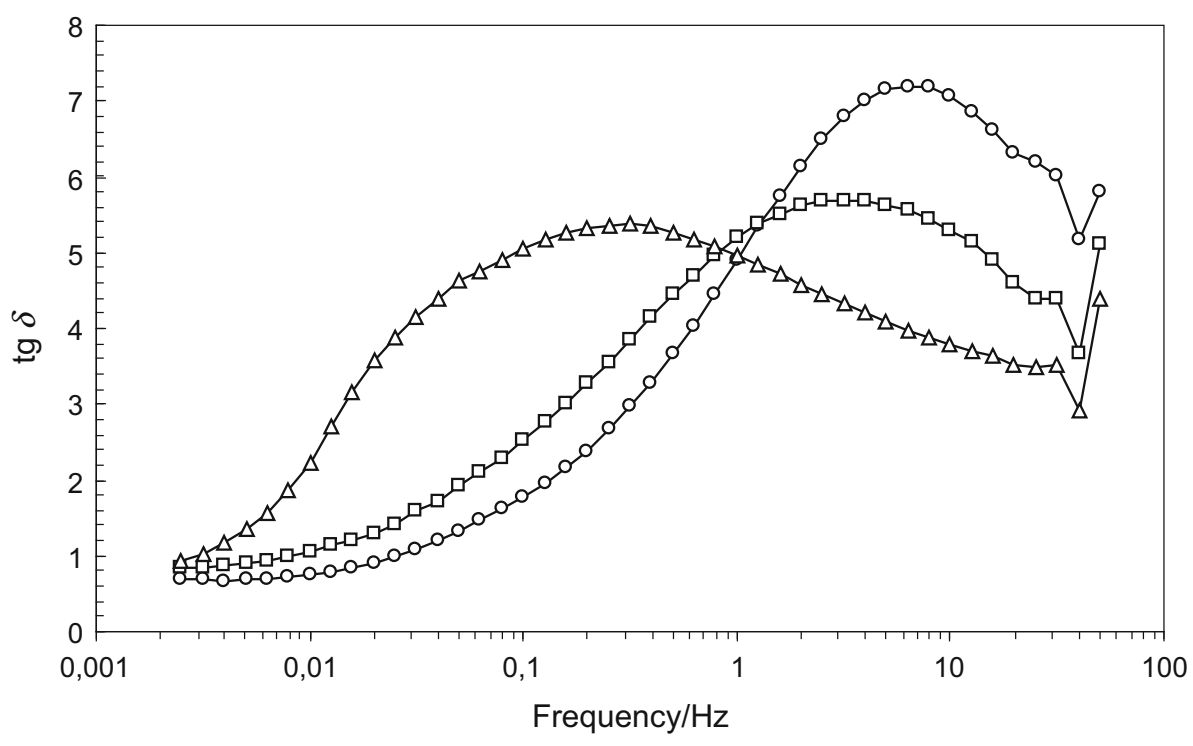

temperature $101.5^{\circ} \mathrm{C}$ caused changes in viscoelastic properties towards the predominance of viscous properties. Increasing the amount added to the pitch caused the intensification of observed changes in properties.

In addition, it was decided to define impact of resin crosslinking time in bitumen on its properties. Tests were performed for compounds containing $25 \%$ of modifying agent by mass, which undergo crosslinking for $0.5-2.0 \mathrm{~h}$, at temperature $160{ }^{\circ} \mathrm{C}$. Properties of these compounds were compared with the composition of coal-tar pitch with $25 \%$ of resin by mass without crosslinking.

Compounds additionally crosslinked in comparison with not crosslinked compound had higher softening temperatures and higher content of components insoluble in quinoline (Table 1). Prolongation of crosslinking time caused increase in softening temperature, particularly for compound crosslinked for $2.0 \mathrm{~h}$. Content of components insoluble in quinoline was increasing along with increase in crosslinking time. It implied the occurrence of chemical reactions leading to formation of components of probably substantial molecular masses, as a result of crosslinking, among others.

Similarly like at the evaluation of the impact of phenolformaldehyde resin amount, also at the evaluation of the impact of crosslinking time the measurements were taken at possibly lowest temperature which minimized further crosslinking of resin. Compounds crosslinked for 0.5 or $1.0 \mathrm{~h}$ had softening temperatures not exceeding $124^{\circ} \mathrm{C}$. Considerable rise of that temperature happened for compounds crosslinked for $2.0 \mathrm{~h}$. For compounds non-crosslinked and crosslinked for 0.5 or $1.0 \mathrm{~h}$, measurements of rheological properties were taken at temperature $118{ }^{\circ} \mathrm{C}$.

Figures 5-8 present selected dependences of rheological properties versus frequency of the pitch compound with $25 \%$ of phenol-formaldehyde resin by mass, non- crosslinked and crosslinked for 0.5 or $1.0 \mathrm{~h}$, determined at temperature $118^{\circ} \mathrm{C}$.

Runs of individual dependencies for all compared compounds containing $25 \%$ of resin by mass were similar. Changes in values of storage and loss modules as well as complex viscosity became greater along with the extension of crosslinking time of the compound (Figs. 5, 6). As for values of phase angle and loss tangent, highest changes versus frequency were present for compound which did not undergo crosslinking; the changes gradually decreased along with the extension of crosslinking time (Figs. 7, 8). Extension of crosslinking time also caused shifting of intersection point of $G^{\prime}, G^{\prime \prime}=f(v)$ curves towards lower frequencies (Table 2).

It was demonstrated that extension of crosslinking time of the compound of coal-tar pitch with phenol-formaldehyde resin caused similar changes in rheological properties like increase in resin content in the compound.

Taking into account the possible application, determination of temperature impact on changes in rheological properties is particularly important for the production of coal products. It is advantageous that the raw material has suitable fluidity and appropriate mechanical resistance. Therefore, assessment of changes in rheological properties versus temperature was carried out for the pitch with $25 \%$ of phenol-formaldehyde resin by mass, crosslinked for $2.0 \mathrm{~h}$. Such compound had high softening temperature while still being the substance susceptible to melting, which characteristics enabled the preparation of suitable samples for tests. The possibility of further crosslinking of the resin at measurement conditions was also minimized in the case of that compound. Determined results for that compound were compared with characteristics of unmodified coal-tar pitch. 
Fig. 5 Dependences of storage versus frequency determined at temperature $118^{\circ} \mathrm{C}$ for compound of the pitch with $25 \%$ of phenol-formaldehyde resin by mass: filled squarepitch/25PF/0 $\left(G^{\prime}\right)$; open square-pitch/25PF/0 $\left(G^{\prime \prime}\right)$; filled rhombus - pitch/25PF/0.5 $\left(G^{\prime}\right)$; open rhombus-pitch/ 25PF/0.5 $\left(G^{\prime \prime}\right)$; filled trianglepitch/25PF/1.0 $\left(G^{\prime}\right)$; open triangle - pitch/25PF/1.0 $\left(G^{\prime \prime}\right)$ $\left(G^{\prime}\right)$ and loss $\left(G^{\prime \prime}\right)$ modules

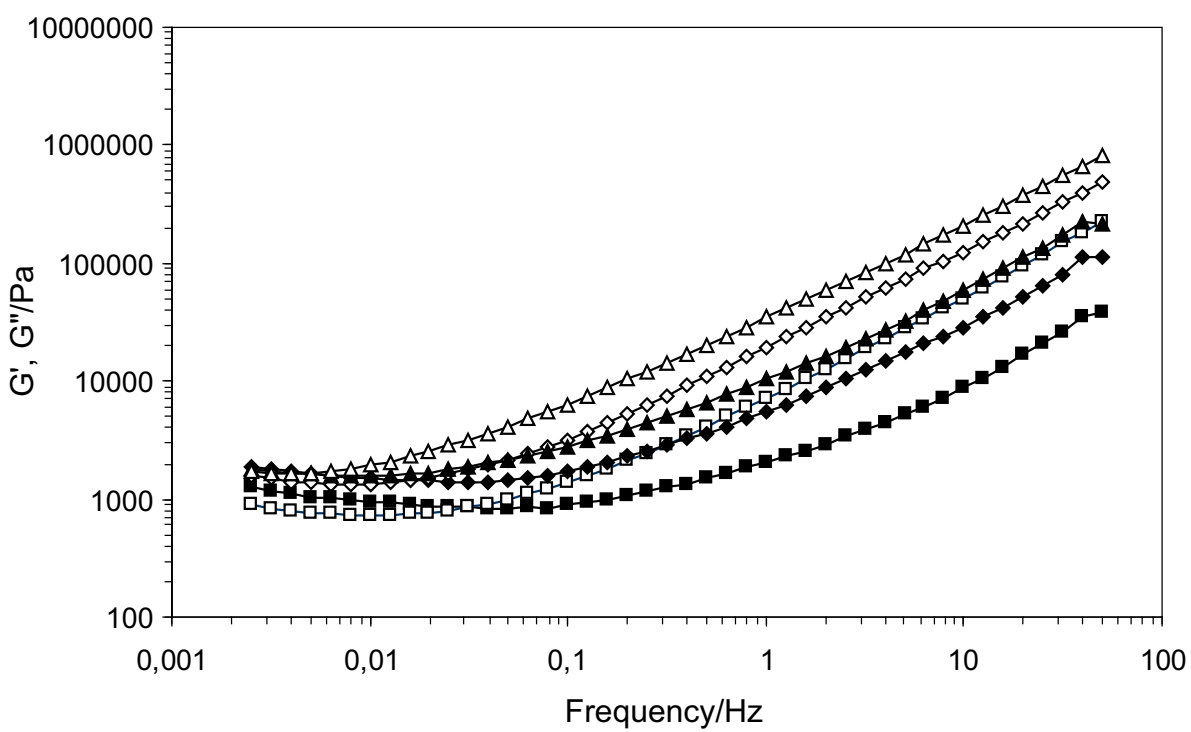

Fig. 6 Dependences of complex viscosity $(|\eta *|)$ versus frequency determined at temperature $118{ }^{\circ} \mathrm{C}$ for compound of the pitch with $25 \%$ of phenol-formaldehyde resin by mass: open squarepitch/25PF/0; open rhombus$\mathrm{pitch} / 25 \mathrm{PF} / 0.5$; open triangle pitch/25PF/1.0

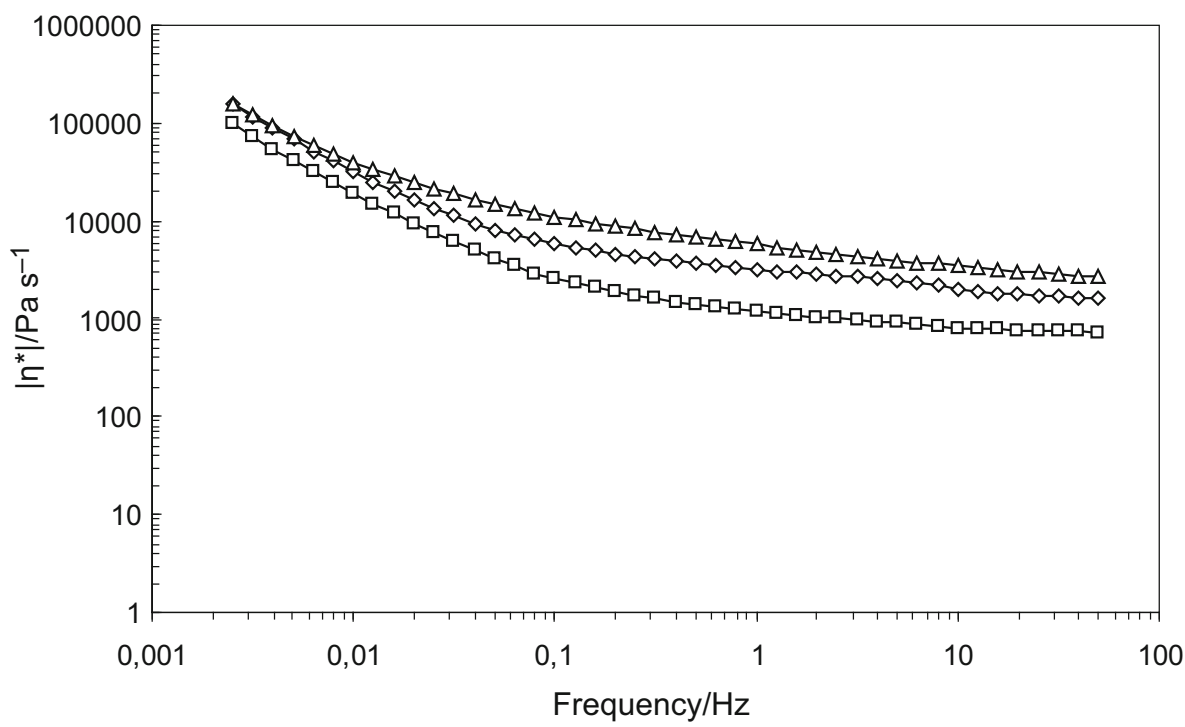

Oscillation measurements of the pitch and the compound of pitch with $25 \%$ of phenol-formaldehyde resin by mass versus temperature were possible at different temperature ranges. It resulted from difference of their softening temperature which determined initial temperature of measurement. Measurement for all configurations was run up to temperature of about $280-320{ }^{\circ} \mathrm{C}$ and was interrupted at too intense vapourization of components of lower boiling point.

Relationships of selected properties versus temperature determined for unmodified coal-tar pitch and the compound containing $25 \%$ of phenol-formaldehyde resin by mass are presented in Figs. 9 and 10.

Based on determined modules (storage $G^{\prime}$ and loss $G^{\prime \prime}$ ), phase angle $(\delta)$ and complex viscosity $\left(\eta^{*}\right)$ versus temperature, it is possible to determine some characteristic temperatures $[6,20]$ for coal materials, i.e. softening temperature, temperature of achievement of minimum complex viscosity and re-solidification temperature.

The temperature relationship of complex viscosity determined for coal-tar pitch implied similar behaviour of the pitch like polymers and thermosetting resins. Viscosity of the pitch, in assumed measuring conditions, was at first significantly decreasing until achieving minimum value, and then was increasing up to reaching a constant value, which situation implied occurrence of re-solidification process. Addition of phenol-formaldehyde resin to the pitch caused changes in the course of viscosity versus temperature dependence. Viscosity of the compound containing phenolformaldehyde resin was insignificantly changing after reaching the minimum value, which practically showed the absence of re-solidification process at measuring conditions 
Fig. 7 Dependences of phase angle versus frequency determined at temperature $118{ }^{\circ} \mathrm{C}$ for compound of the pitch with $25 \%$ of phenolformaldehyde resin by mass: open square - pitch/25PF/0; open rhombus - pitch/25PF/0.5; open triangle - $\mathrm{pitch} / 25 \mathrm{PF} / 1.0$

Fig. 8 Dependences of loss tangent versus frequency determined at temperature $118{ }^{\circ} \mathrm{C}$ for compound of the pitch with $25 \%$ of phenolformaldehyde resin by mass: open square - pitch/25PF/0; open rhombus - $\mathrm{pitch} / 25 \mathrm{PF} / 0.5$; open triangle - pitch/25PF/1.0

Fig. 9 The plots of complex viscosity $(|\eta *|)$ versus temperature determined at frequency of $1 \mathrm{~Hz}$ for compound of the pitch with $25 \%$ of phenol-formaldehyde resin by mass, crosslinked for 2.0 h: open circle-pitch; open triangle - pitch/25PF/2.0
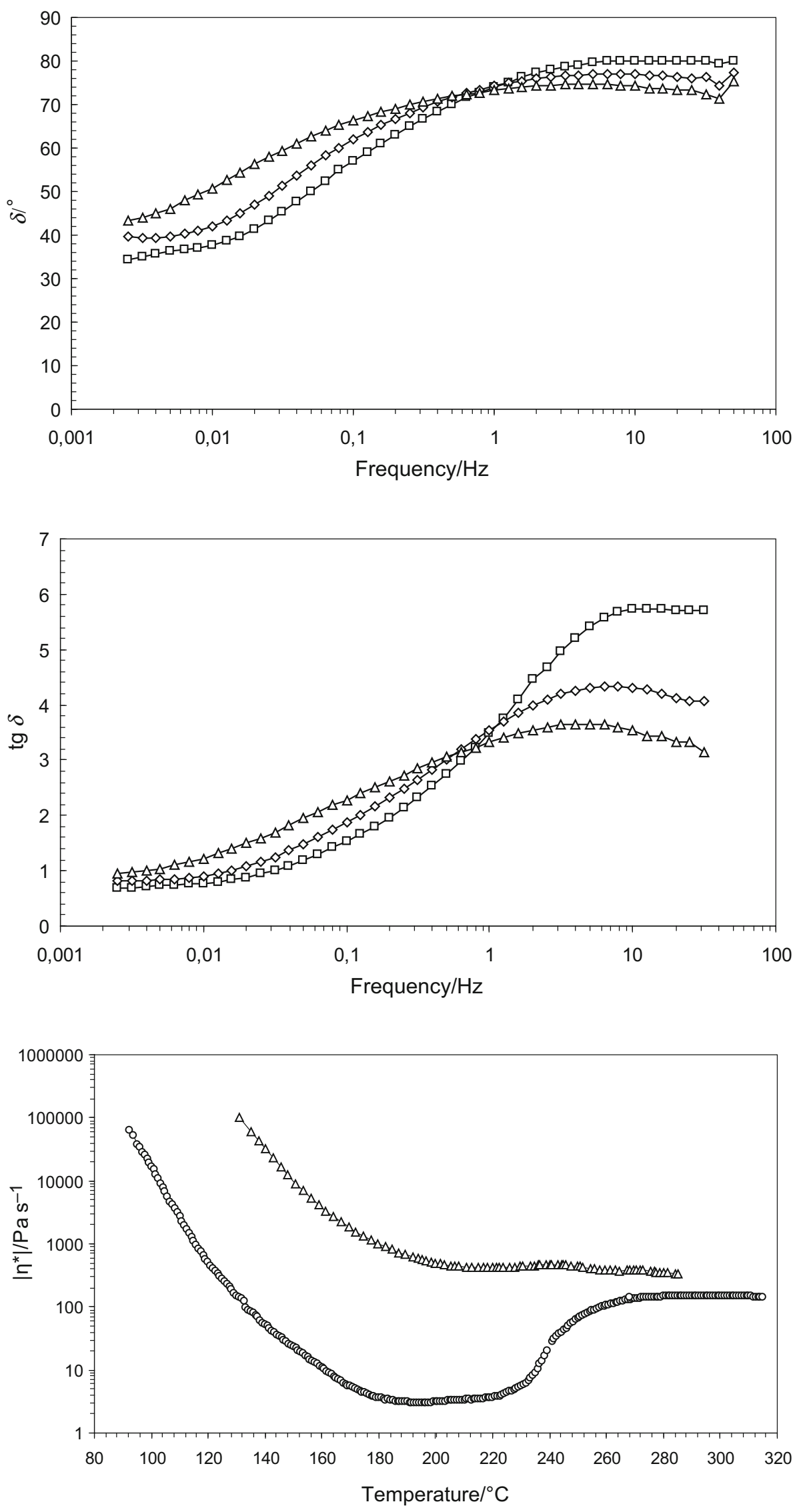
Fig. 10 The plots of phase angle versus temperature determined at frequency of $1 \mathrm{~Hz}$ for compound of the pitch with $25 \%$ of phenol-formaldehyde resin by mass, crosslinked for 2.0 h: open circle - pitch; open triangle-pitch/25PF/2.0

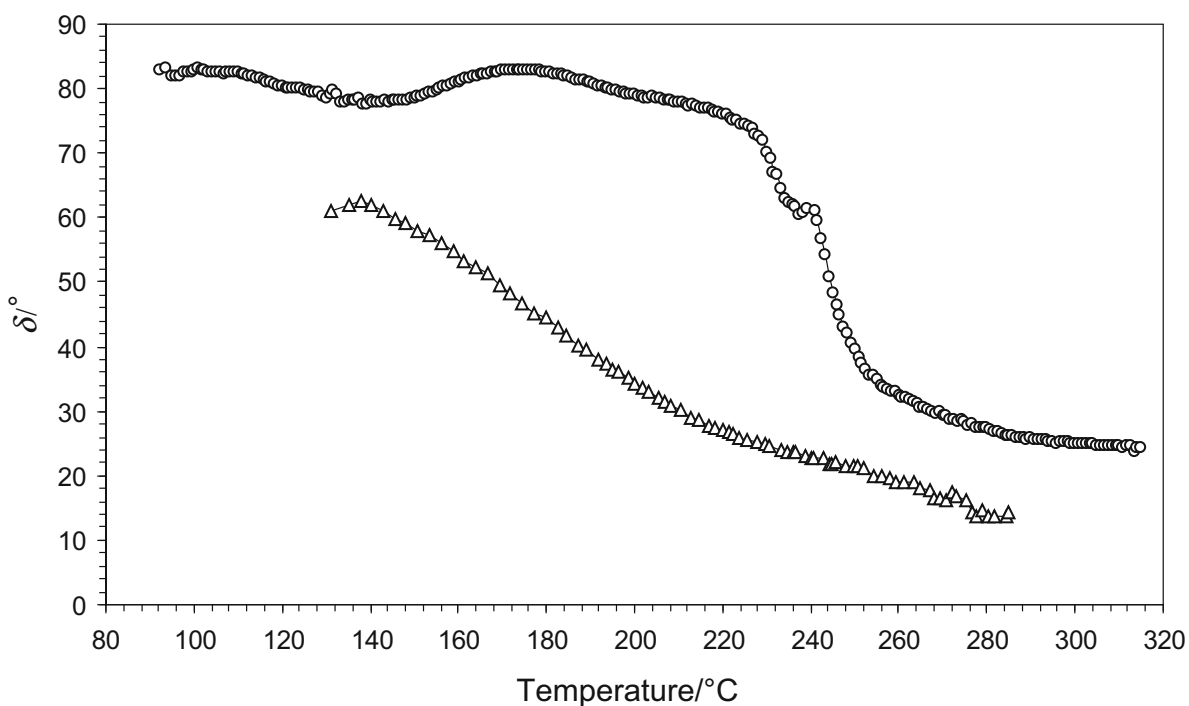

Re-solidification process of the compound of pitch with phenol-formaldehyde resin probably occurs at temperatures above $300{ }^{\circ} \mathrm{C}$. Phenol-formaldehyde resin caused increase in the pitch viscosity, including minimum viscosity, thus reducing its fluidity and increasing the temperature for achieving minimum viscosity.

Addition of phenol-formaldehyde resin to the pitch affected the change in its viscoelastic properties. Coal-tar pitch showed predominance of viscous characteristics at temperature up to $264{ }^{\circ} \mathrm{C}$. Above this temperature, transition from viscous to viscoelastic properties was observed. Values of phase angle were decreasing along with temperature rise for the compound of pitch with phenolformaldehyde resin crosslinked for $2.0 \mathrm{~h}$. These values were considerably lower than values $(\delta)$ determined for coal-tar pitch. Addition of phenol-formaldehyde resin increased the fraction of viscoelastic characteristics of bitumen.

\section{Conclusions}

In the case of coal raw materials, e.g. coals subjected to high-temperature carbonizing process in order to obtain porous materials, it is essential to assure high flowability (low viscosity) at carbonizing conditions as well as appropriate mechanical strength. Addition of polymers to such materials as a rule results in the increase in viscosity and thereby in worsening the flowability [8, 10]. Due to very low viscosity of coal-tar pitch, addition of polymers can-despite the effect of viscosity increase-play an advantageous role, increasing its thermal and mechanical resistance at the same time.

Obtained and presented test results allowed to find that addition of phenol-formaldehyde resin to coal-tar pitch results in rise of softening temperature and viscosity. Together with both increase in resin addition and extension of crosslinking time, changes in evaluated properties became more intense. Structures of probably higher average molecular mass and lower solubility in quinoline were formed at applied conditions of homogenization and crosslinking of the pitch with phenolformaldehyde resin.

Increasing the amount of components insoluble in quinoline in the pitch due to the addition of phenolformaldehyde resin is not advantageous phenomenon in the point of view of producing such materials like carbon fibres. Coal-tar pitch modified with phenol-formaldehyde resin can be used as the precursor for the production of porous materials. Due to considerable thermal and mechanical resistance, it seems that the compounds containing minimum $25 \%$ of phenol-formaldehyde resin by mass, favourably crosslinked for $2.0 \mathrm{~h}$, are most suitable for that purpose.

Open Access This article is distributed under the terms of the Creative Commons Attribution 4.0 International License (http://crea tivecommons.org/licenses/by/4.0/), which permits unrestricted use, distribution, and reproduction in any medium, provided you give appropriate credit to the original author(s) and the source, provide a link to the Creative Commons license, and indicate if changes were made.

\section{References}

1. Zieliński J, Osowiecka B, Liszyńska L, Ciesińska W, Polaczek J, Kubica K. Benzo[a]pyrene in coal tar-pitch: chemical conversion in situ by alkylation. Fuel. 1996;75:1543-8.

2. Zieliński J, Osowiecka B, Liszyńska B, Ciesińska W, Polaczek J, Machowska Z. Coal-tar pitch/polymer blend with reduced benzo[a]pyrene content and a method for preparing it. PL 189817 B1. 1996. 
3. Zieliński J, Osowiecka B, Ciesińska W, Liszyńska B, Brzozowska $\mathrm{T}$. The effect of a polyester resin or polyoxyethylene glycols as coal-tar pitch modifiers on pitch's benzo[a]pyrene content. Polimery. 1998;43:175-84.

4. Diaz MC, Edecki L, Steel KM, Patrick JW, Snake CE. Determination of the effects caused by different polymers on coal fluidity during carbonization using high-temperature ${ }^{1} \mathrm{H}$ NMR and rheometry. Energy Fuels. 2008;22:471-9.

5. Takanohashi T, Yoshida T, Iino M, Katoh K. Temperature-variable dynamic viscoelastic measurement for coals. Fuel. 1999;78:865-6.

6. Ciesińska W. Rheological characteristics of some coal liquids. Przem Chem. 2012;91:2164-7.

7. Duffy JJ, Diaz MC, Snake CE, Mahoney MR, Steel KM. Combined use of rheometry and microscopy to understand pore structure development during coal carbonization. In: International Conference on Coal Science and Technology. Nottingham; 2007. $2 \mathrm{P} 36$.

8. Ciesińska W. The rheological properties of coal bitumens modified by polyesters. Polimery. 2015;60:144-6.

9. Zieliński J, Ciesińska W. Investigations on the effect of unsaturated polyester resins on rheological properties of coal tar pitch. Polimery. 1999;44:764-74.

10. Ciesińska W. The effect of poly(terephthalate ethylene)addition on rheological properties of coal tar pitch. Przem Chem. 2010;89:1107-10.

11. Makomaski G, Ciesińska W, Zieliński J. The use of waste poly(ethylene terephthalate) and phenol-formaldehyde resin for the preparation of activated carbons. Polimery. 2012;57:635-9.

12. Makomaski G, Ciesińska W, Zieliński J. Thermal properties of pitch-polymer compositions and derived activated carbons. J Therm Anal Calorim. 2012;109:767-72.
13. Szychowski D, Pacewska B, Makomaski G, Zieliński J, Ciesińska W, Brzozowska T. Adsorption and DSC study of mineral-carbon sorbents obtained from coal tar pitch-polymer compositions. J Therm Anal Calorim. 2012;107:893-900.

14. Noparvar-Qarebagh A, Roghani-Mamaqani H, Salami-Kalajahi $\mathrm{M}$, et al. Nanohybrids of novolac phenolic resin and carbon nanotube-containing silica network. J Therm Anal Calorim. 2017;128:1027-37. doi:10.1007/s10973-016-5970-0.

15. Asaro L, D'Amico DA, Alvarez VA, et al. Impact of different nanoparticles on the thermal degradation kinetics of phenolic resin nanocomposites. J Therm Anal Calorim. 2017;128:146378. doi:10.1007/s10973-017-6103-0.

16. Haddadi SA, Kardar P, Abbasi F, et al. Effects of nano-silica and boron carbide on the curing kinetics of resole resin. J Therm Anal Calorim. 2017;128:1217-26. doi:10.1007/s10973-016-5951-3.

17. Szychowski D, Pacewska B. Methods of preparation and properties of mineral-carbon sorbents obtained from coal-tar pitchpolymer compositions. J Therm Anal Calorim. 2012;109:789-95. doi:10.1007/s10973-012-2341-3.

18. Barnes HA. A handbook of elementary rheology. Aberystwyth: University of Wales Institute of Non-Newtonian Fluid Machanics; 2000.

19. Li T, Liu X, Wang C, Wang H. Structural characteristics of mesophase spheres prepared from coal tar pitch modified by phenolic resin. Chin J Chem Eng. 2006;14:660-4.

20. Nomura S, Kato K, Komaki I, Fujioka Y, Saito K, Yamaoka I. Viscoelastic properties of coal in the thermoplastic phase. Fuel. 1999;79:1583-9. 